\title{
REDDITOR LVCIS AETERNAE: Constâncio Cloro e a Reconquista da Britânia
}

\author{
Diogo Pereira da Silva* \\ Érika Vital Pedreira*"
}

\begin{abstract}
SILVA, D.P.; PEDREIRA, E.V. REDDITOR LVCIS AETERNAE: Constâncio Cloro e a Reconquista da Britânia. R. Museu Arq. Etn., São Paulo, 22: 123-135, 2012.
\end{abstract}

Resumo: A partir da discussão sobre as características da dominação romana na Britânia, buscamos examinar a construção da retórica imperial em torno da reconquista desta província pelo imperador Constâncio Cloro, no ano 296. Em especial, analisaremos as demonstrações do fausto imperial através das moedas e dos panegíricos que representaram Constâncio Cloro como o redditor lucis aeternae.

Palavras-chaves: Império Romano, Britânia, Constâncio Cloro, Caráusio

\section{A Britânia e o Império Romano}

$\mathrm{N}$ este artigo temos por objetivo analisar a construção da retórica imperial romana sobre a reconquista da Britânia pelo imperador romano Constâncio Cloro (293-306), no ano 296, difundida através de suportes materiais numismáticos e por discursos laudatórios. Não obstante, como ponto inicial, estabeleceremos uma análise dos primeiros contatos entre os povos locais desta província e os romanos, assim como os resultados de tais interações.

Em nossas análises acerca desses contatos entre os romanos e os povos locais, partimos dos

(*) Doutorando em História Comparada pela Universidade Federal do Rio de Janeiro (PPGHC-UFRJ), orientado pela Profa. Dra. Norma Musco Mendes. Professor da Universidade Salgado de Oliveira (Niterói/RJ).

(**) Mestranda em História Antiga e Medieval pela Universidade Federal Fluminense (PPGH-UFF), orientada pela Profa. Dra. Adriene Baron Tacla. Bolsista de mestrado do CNPq. pressupostos da teoria pós-colonial, posto que buscamos compreender as ações desses povos frente à inserção de elementos da cultura imperial romana em seus territórios. Por conseguinte, nos baseamos nos trabalhos desenvolvidos por Edward Said (1995) e Homi Bhabha (2007) para analisar como a cultura romana e as culturas locais interagiram, e de que forma elementos e práticas culturais foram mantidos, negociados $\mathrm{e}$ ressignificados nesse contexto de contato.

Em Cultura e Imperialismo, Said afirmou que a dominação pode ser alcançada e mantida através de meios não coercitivos, como, por exemplo, as relações culturais. Nesse caso, a dependência de um dado território a uma potência sobrevive graças a determinadas práticas políticas, sociais e ideológicas, ou seja, um âmbito cultural geral (Said, 1995:40).

Conforme proposto por Edward Said (Said, 1995:46), as culturas não são fechadas e impenetráveis, ao contrário, estão em constante transformação, uma vez que carregam marcas 
de diferentes experiências e contatos. Nesse sentido, podemos compreender que os elementos de uma determinada cultura ganham novos sentidos e novos usos quando inseridos em uma cultura diferente. Entendemos esses novos usos como uma transgressão da ordem imposta, a fim de adequá-la às necessidades específicas de um novo contexto cultural.

Homi Bhabha designa tal processo como negociação, que ocorre no cotidiano, e muitas vezes de forma imperceptivel. Desse modo, o colonizado está a todo momento atribuindo novos usos a elementos diversos, que lhes chegam através das relações entre a sua cultura e a cultura do colonizador (Bhabha, 2007:52).

Esse processo poder ser compreendido como "hibridismo cultural", ou seja, a identidade se constrói durante ligações e negociações, que geram ressignificações dos símbolos culturais tradicionais, não existindo uma soberania cultural, mas sim culturas híbridas, as quais são dinâmicas e abertas.

Neste artigo, atribuímos este processo de negociação aos contatos entre romanos e as populações locais da Britânia, ainda que, em um primeiro momento tenha existido o conflito direto - algumas revoltas - percebe-se em um segundo momento, através da cooptação das elites locais, a construção de uma cultura entendida por nós como híbrida, visto que seus elementos e características não podem ser analisados isoladamente como pertencendo a uma ou outra sociedade.

Entre os anos 55 e 54 a.C., em decorrência das campanhas desenvolvidas por Júlio César através da Gália, observamos os primeiros contatos entre os romanos e os habitantes das Ilhas Britânicas (César. Sobre a Guerra das Gálias. IV, 20-38; Dião Cássio. História de Roma. XXXIX. 50-53; XL, 1-3; Tácito. Agrícola. 13).

Nesse período inicial dos contatos, observa-se uma separação entre as tribos que se aliaram aos romanos - em geral, as tribos localizadas no sudeste da ilha - e tribos inimigas de Roma. Os aliados de Roma, em curto prazo, passaram a ter acesso às redes comerciais romanas que interligavam aquela região ao comércio mediterrânico e, inclusive, iniciaram um processo de utilização e cunhagem de moedas (Potter. Johns, 2002:30-31).

A análise das moedas cunhadas na Britânia neste período - muitas das quais carregavam os nomes de seus chefes locais -, nos permite defender a hipótese da existência de um aumento da demanda por artigos de luxo - como vinho, azeite, garum, ${ }^{1}$ além de utensílios de cerâmica, como copos e vasos (Potter. Johns, 2002:30).

Não obstante a existência desses primeiros contatos entre romanos e bretões, foi apenas após a conquista efetiva da Britânia - ocorrida com a campanha promovida pelo imperador Cláudio, no ano 43 (Tácito. Agrícola. 13) -, que podemos afirmar que a Britânia passou a integrar o sistema imperial romano.

A partir desse período, foram estabelecidas relações diplomáticas e amigáveis com alguns chefes locais, o que auxiliou no avanço da conquista romana no interior da Ilha. Tais chefes eram reconhecidos como "reis-clientes", que, apesar de ainda pertencerem ao cenário político-religioso de suas tribos, passaram a ser clientes de Roma e tinham o dever de auxiliá-la na manutenção da paz no Império (Webster, 1993:113)

Segundo Graham Webster (1993: 113), um "reino-cliente" - como, por exemplo, a tribo dos icenos e a tribo dos atrebates - tinha liberdade de manter suas próprias leis e independência, enquanto gozava da proteção conferida por Roma contra possíveis ataques externos.

Conforme proposto por Norma Mendes e Yuri Araújo (2007:263-265), podemos compreender que a ação romana na Britânia instituiu uma nova lógica de organização espacial, que se fez refletir também na organização social, ao inserir membros das elites locais em um novo complexo administrativo através da obtenção da cidadania e aquisição de cargos públicos municipais.

(1) O garum era um molho feito à base de peixe (sangue, vísceras e outras partes selecionadas do atum ou da cavala misturadas com peixes pequenos, crustáceos e moluscos esmagados), sal e ervas aromáticas; tudo isto era deixado em salmoura e ao sol durante cerca de dois meses ou então aquecido artificialmente, exportado em ânforas para Roma e para todo o Império. http://algarvivo.com/arqueo/index.html 
Não obstante, a Britânia manteve-se como uma das regiões mais "resistentes" à dominação romana, apresentando momentos de revolta armada, usurpações e manutenção de práticas religiosas locais. Para Martin Millet (2005), isso se deu graças ao relativo isolamento geográfico da Britânia em relação às demais províncias do Império Romano.

As ações de Agrícola, governador entre 77-84 d.C., relatadas por Tácito, influíram na historiografia criando imagens de uma Britânia pacificada quase que por completo, urbanizada e organizada (Davidson, 2004:151). Porém, as fontes clássicas demonstram que a conquista da Britânia se realizou em um processo lento e gradual, e conforme as pesquisas de Jorge Davidson (2004), a Britânia só ganhou maior coesão durante o século II d.C.

Segundo Greg Woolf (2001:314-315), a dominação fez com que os povos conquistados passassem a conviver com uma nova paisagem e novas relações sociais correspondentes às representações que integravam o projeto cultural romano. Nesse âmbito também podem ser incluídas a construção de templos - antes escassos na paisagem da Britânia e a mudança nas representações iconográficas das divindades, que passaram a ser representadas antropomorficamente.

Cabe ressaltar aqui que a grande extensão territorial, bem como a diversidade cultural do Império Romano, levou à necessidade da criação de mecanismos de integração das áreas conquistadas. Verificamos, assim, a tentativa de se estabelecer um código cultural em comum, que fosse acessivel e que pudesse ser compartilhado por todos os habitantes do Império. A reorganização espacial das províncias e a política religiosa romana, pautada na tolerância de práticas locais, representam alguns desses mecanismos.

Entretanto, a dominação da província não ocorreu apenas de forma coercitiva, através da força e poderia militar. Os processos de Romanização também foram facilitados pela constante presença do poder imperial e pela construção de um espaço social privilegiado que congregasse diversos símbolos, que conseguissem seduzir as sociedades locais a segui-los e compartilhá-los (Mendes, Araújo, 2007: 263).
A ciuitas foi esse espaço privilegiado, propício para concentrar populações e controlar os fluxos de pessoas, mercadorias e moedas, visto que suas construções geravam um reordenamento visual e espacial que auxiliava na criação de elementos em comum em todas as regiões do Império, inserindo os habitantes das províncias no modelo e lógica romanos. Dessa forma, a cidade romana ou ciuitas era a principal forma de difundir a Humanitas. ${ }^{2}$ Segundo Davidson (2004), a intervenção no espaço comunicava visualmente a hegemonia do Império, prescrevendo condutas e estabelecendo símbolos que fossem reconhecidos em todas as regiões.

As cidades eram organizadas a partir de uma hierarquia no interior da província, e cada cidade possuía seu estatuto sociojurídico, definido pela quantidade de instituições romanas que possuísse. As cidades, assim, variavam de acordo com o seu posicionamento perante o governo provincial.

As colônias, por exemplo, consistiam em uma cidade de padrão romano, habitada por veteranos do exército imigrante, que possuíam a cidadania completa e sua administração reproduzia a base da organização institucional romana. (Mendes, 2006: 243). As colônias serviam como centros administrativos das províncias.

Segundo Richard Hingley (2006, p.70), a colônia estabelecida em Camulodunum - atual Colchester - foi construída exatamente nos padrões arquitetônicos romanos e contava com o maior templo e o maior teatro da província da Britânia. A colônia se tornou o centro do governo local, além de possuir estradas pavimentadas e um complexo com fórum e basílica. O templo de Cláudio encontrado em Camulodunum indica que a cidade operava como centro do culto imperial na província, antes da revolta de Boudicca entre os anos 60 e 61 d.C.

Os municipia eram assentamentos locais preexistentes, que passaram a ser organizados

(2) Podemos relacionar à ideia de civilização o termo latino mais próximo da nossa noção de cultura. Pode ser definido pela junção de dois aspectos: interno, conhecimento adquirido através dos estudos, e externo, sistema de valores éticos e morais transmitidos de geração a geração e consagrados pela tradição dos ancestrais (mos maiorum). (MENDES, ARAÚJO. 2007, p. 278). 
sob o modelo romano. Os municipia, embora estivessem sob a autoridade romana, preservaram certo grau de autonomia em seus costumes locais e administração. Possuíam, contudo, encargos financeiros e militares com Roma. As reconstruções feitas de Verulamium - atual Saint Alban - indicam que esta se tratava de um municipium, provavelmente o único da Britânia.

De acordo com Hingley (2006: 90), as evidências de escavações indicam que a elite de Verulamium recebeu a cidadania romana e mantinha um bom relacionamento com a metrópole, estabelecendo-se como uma cidade próspera durante os anos de conquista.

Ademais, Richard Hingley (2006: 83) ressalta, ainda, que Londinium - atual Londres - era um importante centro comercial. Nessa cidade não existiam muitos assentamentos romanos, nem evidências de uma ocupação pré-romana, sendo alguns poucos e pequenos sítios encontrados ao sul do rio Tâmisa. Esse rio era um importante meio de comunicação e troca entre populações próximas à região sul das Ilhas, além disso, a circulação de pessoas também era facilitada pelo amplo sistema de estradas.

Igualmente, havia algumas indústrias de produção de cerâmica e um sistema de distribuição de água encanada durante o primeiro século; entretanto, não foram encontrados prédios públicos ou de grande porte.

Não obstante, também havia diversos outros assentamentos locais que mantiveram suas próprias leis e características, mas estavam sujeitos à tributação e não possuíam direitos civis, políticos ou fiscais. Nesse ponto, Hingley (2010:53-55) nos chama a atenção para o estudo das áreas rurais da Britânia Romana e sua organização, uma vez que o campo era o local onde vivia a maior parte da população da província e onde os processos de Romanização se deram de forma menos efetiva, visto que foram mantidas formas de assentamento locais, demonstrando que a contribuição romana na Britânia não ocorreu de maneira uniforme e integral.

Essa hierarquização das formas de assentamentos facilitava a cooptação de membros da população local, que buscavam uma maior interação com Roma, a fim de obter a cidadania e status elevado nas províncias. Através da lógica do prestígio, as autoridades imperiais visavam a atrair as elites provinciais, inserindo-as em uma rede de alianças com Roma. Segundo Mendes e Araújo (2007: 265), a rede de interdependências entre as elites cêntricas e locais auxiliou na consolidação da conquista também em âmbito ideológico.

No entanto, como nos afirmam Salway (1993:131;149;150;151;167;168), entre os anos 117 e 119, verifica-se uma série de insurreições e invasões na parte norte da Britânia. Em tal contexto, a manutenção da segurança na província tornava-se cada vez mais onerosa para Roma.

Em uma tentativa de solucionar essa questão, o imperador Adriano (117-138) cessou as expedições para o norte e promoveu a construção de uma barreira física - a Muralha de Adriano -, a fim de dividir as regiões já conquistadas das regiões hostis à presença romana. Durante o governo de seu sucessor, Antonino Pio (138161), houve ainda uma nova tentativa de expansão dos domínios para o norte, a qual resultou na construção da Muralha de Antonino.

Com o fim das invasões, o século II foi marcado pelo desenvolvimento e prosperidade das cidades do sul da Britânia (Millet, 1992:107). Contudo, a relativa paz durou até o ano 193, quando durante o contexto da crise sucessória aberta pela morte de Cômodo, Clódio Albino, governador da província, se envolveu em uma disputa pelo poder imperial.

Albino recebeu o apoio das legiões da Britânia e da Hispânia, proclamando-se "César". Em Roma, o general africano Septímio Severo, já havia, anteriormente, se declarado imperador, o que levou a uma disputa entre o seu exército e o exército sob o comando de Albino.

Vitorioso, para impedir novas usurpações e facilitar a administração e defesa das fronteiras do norte, Severo, já no início do século III, dividiu a província em duas partes, Britânia Superior - parte sul da Ilha - e Britânia Inferior - parte norte da Ilha (Millet, 1992:131).

Em 260, a província da Britânia se viu envolvida em mais um episódio de secessão, dessa vez, Marco Cassiano Latínio Póstumo se declarou imperador na Gália, fundando o Império das Gálias, o qual compreendia as províncias da Gália, da Britânia e partes da Hispânia e Germânia (Christol, 2006: 149-151). 
Esse império sobreviveu até 274, quando o imperador Aureliano (270-275), após uma série de campanhas militares, derrotou seu último governante, reintegrando as regiões usurpadas ao Império Romano (Cizek, 1994, pp. 103-122; Watson, 1999, pp. 57-100).

\section{As trajetórias imperiais de Caráusio e Alecto}

Embora o imperador Aureliano (270-275) tenha restabelecido o domínio romano sobre o Ocidente - ao pôr fim ao "Império das Gálias" -, observamos que os povos germânicos continuaram a exercer forte pressão no limes do rio Reno, juntamente com ações de pirataria no mar do Norte, aterrorizando as costas da Gália Bélgica, da Armórica e da Britânia.

Nesse contexto se iniciou a odisseia do menapiano Marco Aurélio Mauseo Caráusio, que recebeu do imperador Maximiano Hercúleo a tarefa de comandar as forças navais romanas na região do Canal da Mancha, e submeter os piratas francos e saxões (Aurélio Victor. De Caesaribus. 39, 20; Eutrópio. Breviário. IX, 21).

Segundo os relatos dos epitomistas do século IV, Caráusio foi bastante efetivo em sua tarefa, derrotando e subjugando os piratas germânicos; além disso, conseguiu recuperar muito do botim dos saques que esses efetuaram nas cidades costeiras da Gália e da Britânia. Entretanto, ao invés de encaminhar o botim para o tesouro imperial, Caráusio se apropriou das riquezas, causando a ira de Maximiano Hercúleo, que ordenou a sua execução (Aurélio Victor. De Caesaribus. 39, 21; Eutrópio. Breviário. IX, 21).

Em vista desta situação, no ano 287, Caráusio organizou as suas tropas e se refugiou na Britânia, mantendo o domínio sobre a ilha e o norte da Gália, em torno da cidade Gesoriacum - atual Boulogne. A resposta do poder central, controlado por Diocleciano e Maximiano, porém, não pôde ser feita prontamente, pois estes estavam envolvidos em outros problemas na África e no Oriente.

O domínio de Caráusio sobre estas regiões do Império Romano durou cerca de seis anos, até que, após a retomada de Boulogne - pelas tropas de Constâncio Cloro (293-306) -, seguiu-se uma rebelião liderada por Alecto (293-296) - o rationalis summae rei de Caráusio - que executou seu chefe, e fugiu para a Britânia, onde estabeleceu seu quartel-general na cidade de Londinium, atual Londres.

Alecto manteve o domínio da ilha pelos próximos três anos, até que as tropas de Constâncio Cloro, lideradas pelo seu prefeito do pretório Asclepiodoto, tomaram os principais pontos costeiros da Britânia, levando Alecto a cometer suicídio após a batalha.

Após rápida narrativa de alguns pontos factuais importantes, podemos propor certos questionamentos sobre pontos importantes das trajetórias de Caráusio e Alecto.

Por conseguinte, apresentamos ao exame três questões principais: (1) o caráter legítimo ou ilegítimo do poder imperial de Caráusio; (2) a existência de um desejo separatista por parte de Caráusio; e (3) se Alecto apresentou algum tipo de ruptura com as propostas políticas ou tipos de representação de seu antecessor.

Os documentos escritos contemporâneos são categóricos ao creditar Caráusio - jamais nomeado, e sempre denominado "o pirata" como um usurpador ilegítimo, conforme aparece nos Panegíricos Latinos (X(2) 12,1; VIII(4) 12, 1).

Entretanto, segundo as informações posteriores presentes em Aurélio Victor e Flávio Eutrópio, o domínio de Caráusio fora consentido por Diocleciano e Maximiano Hercúleo, que firmaram com ele um tratado de paz, uma vez que Caráusio seria o governante mais apto a defender a região das ameaças de povos hostis (Aurélio Victor. De Caesaribus. 39,39; Eutrópio. Breviário. IX,22).

Certamente, não podemos perder de vista a conjuntura política e institucional do Império Romano do século III, marcada por uma série de conflitos externos e guerras civis. Diocleciano, ao tomar o poder, e estabelecer uma Diarquia com Maximiano, baseou seu poder em torno de certas práticas políticas, em especial a relação de concórdia entre os governantes legítimos.

Nesse sentido, apresenta-se a seguinte proposição: Caráusio foi tolerado por Diocleciano que não dispunha de condições materiais para efetuar uma resposta direta à sua usurpação. 
Todavia, Caráusio não foi considerado um imperador legítimo por Diocleciano.

Isso parece ter ficado bem claro após a tentativa frustrada de Maximiano em invadir a Britânia, possivelmente, no ano 290, que foi amplamente anunciada pelo orador Mamertino em seu panegírico, datado do ano 289 (Panegíricos Latinos. X(2) 12,1-6) - mas, devido ao seu completo fracasso, não foi mencionada no panegírico seguinte, pronunciado em 291 (Panegíricos Latinos. XI(3)).

Para uma apreensão mais direta do ideário político de Caráusio - que não é apontado nos documentos escritos -, devemos lançar mão da documentação de cultura material, em especial as várias séries de moedas que esse imperador cunhou durante o seu governo.

Caráusio e posteriormente Alecto utilizaram dois centros principais de cunhagem: as cidades de Londinium e Camulodunum, atual Colchester, na Inglaterra. A maior parte das moedas conhecidas de Caráusio foi encontrada em baús enterrados na Inglaterra, conforme as considerações de P. H. Webb (1908:448-453), H.P.G. Williams (2004).

Ademais, grande parte desses achados foi datada de finais do século III, época da reconquista da Britânia por Constâncio Cloro, e revelam o sentimento de medo e a busca do entesouramento de grandes somas de moedas nesses tempos de crise institucional e de guerras.

No presente trabalho, tomamos por base o catálogo numismático estabelecido por P.H. Webb, em 1908, e que compõe o Volume V, parte II, da coleção The Roman Imperial Coinage. Em tal obra, foram catalogadas 1097 tipologias monetárias diferentes cunhadas por Caráusio, frente a 132 tipologias diferentes cunhadas por Alecto.

A cunhagem de moedas de Caráusio se limitou aos anos em que governou, entre $287 \mathrm{e}$ 293, e apresenta uma série de similaridades com a cunhagem imperial de Maximiano Hercúleo e Diocleciano. A onomástica e a titulatura imperiais adotadas por Caráusio é similar àquela então empregada pelos diarcas, sendo predominante a denominação IMP CARAVSIVS PIVS
FELIX AVGVSTVS (Imperador Caráusio, o Pio, o Feliz, Augusto).

Em relação aos temas de reversos mais comuns nas emissões de Caráusio, predominam as tipologias da Pax, da Felicitas, da Concordia, da Fides, da Virtus, da Providentia, dos deuses Mars, Iuppiter, Hercules, além de outras pouco cunhadas como Roma Aeterna, Oriens Augusti, Aduentus Augusti.

Além dessas inscrições de reverso, uma imagem comum nas emissões monetárias de Caráusio é a representação de um trirreme, que demonstra a importância conferida por este governante à sua frota, que permitia a ele manter o controle e a defesa de seus territórios, a submissão dos piratas germânicos, e uma vantagem estratégica frente a Maximiano Hercúleo e Diocleciano.

Em relação a essa tipologia, remetemos à Moeda 1 - cunhada na cidade de Londinium na qual se encontra a representação imagética e onomástica estereotipada de Caráusio, e no reverso a imagem de um trirreme com quatro remadores, e a legenda FELICITAS AVGVSTI (Felicidade do Augusto).
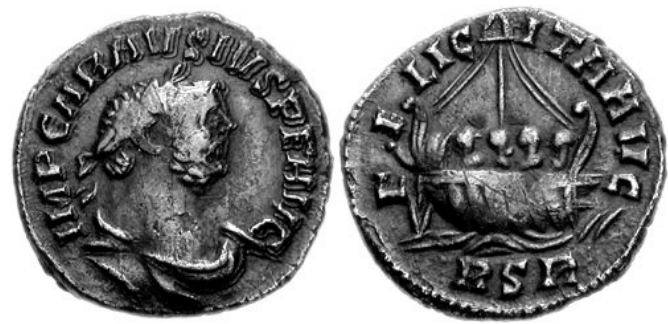

Moeda 1

- Datação: Londres, 287. AR / Denarius.

- Anverso: Caráusio, lauredo, colgado, à direita.

- Legenda: IMP CARAVSIVS P F AVG

- Tradução: Imperador Caráusio, o Pio, o

Feliz, Augusto

- Reverso: Galera com um mastro central, navegando sobre as ondas, quatro remadores.

- Legenda: FELICITA AVG

- Tradução: Felicidade do Augusto.

- Exergo: RSR.

- Indicação: RIC V Carausius 560.

- Escala: 3:1 
Certamente, a legenda de reverso dialoga com a onomástica adotada por Caráusio. $\mathrm{O}$ termo latino Felicitas nos reporta à bem-aventurança divina, demonstrando que o imperador é um ser escolhido pelos deuses, um Felix. Esta bem-aventurança se manifestava nos triunfos militares sobre os invasores e piratas, demonstrando que ele era um ser apto para ser imperador.

Outra característica que podemos depreender desta onomástica é a ênfase na pietas Augusti. Pietas significa a relação correta existente entre os homens e os deuses, advinda da realização de rituais religiosos, como sacrifícios e libações, que garantiam os favores divinos ao imperador (Ando, 2008: 1-19; Rives, 2007: 148-157).

Essa proposta de representação do poder imperial, entretanto, não foi uma novidade introduzida por Caráusio. Desde meados do século III, os imperadores passaram a adotar tal onomástica, que era então utilizada nas emissões monetárias de Diocleciano e Maximiano Hercúleo.

Outrossim, Caráusio adotou um dos principais ideários dos diarcas em suas emissões monetárias, o termo concordia. A concordia foi um dos pilares do sistema político de gestão colegiada erigido por Diocleciano, e que posteriormente foi desdobrado de uma Diarquia para uma Tetrarquia. A concordia permitia que dois ou mais imperadores compartilhassem o poder imperial, sem o medo de guerras civis como ocorreram durante o século III.

Por certo, Diocleciano fez da concordia o fundamento da unidade do poder imperial, e da submissão de Maximiano Herculeo e, posteriormente, dos demais tetrarcas - Constâncio Cloro e Galério (293-311).

Das oficinas dos domínios de Caráusio advêm vários exemplos de moedas que emulavam a concórdia imperial, como, por exemplo, a Moeda 2. Neste exemplar (RIC V-2 207) cunhado em Londinium, observamos a legenda CONCOR MI (Concordia Militum, Concórdia dos Soldados) com a representação de duas mãos dadas, como em cumprimento. Da mesma forma que demonstra a concórdia existente entre Caráusio e seus soldados, demonstra a apropriação de um tema caro a Diocleciano, ou mesmo a busca de uma aproxi-

mação por parte de Caráusio, anulando qualquer hipótese de separatismo.
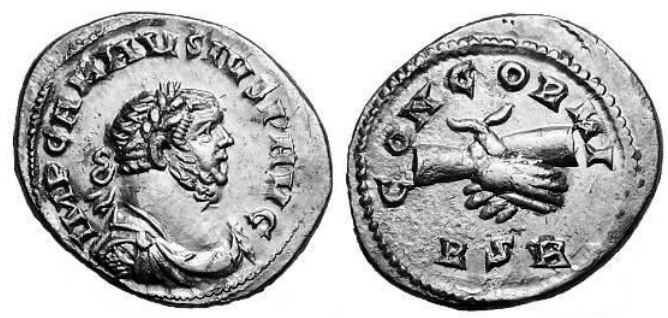

Moeda 2

- Datação: Londres, 287-293. AR / Denarius.

- Anverso: Caráusio, lauredo, colgado, encouraçado, à direita.

- Legenda: IMP CARAVSIVS P F AVG

- Tradução: Imperador Caráusio, o Pio, Augusto

- Reverso: Duas mãos em saudação.

- Legenda: CONCOR MI

- Tradução: Concórdia dos Soldados

- Exergo: RSR.

- Indicação: RIC V Carausius 593.

- Escala: 3:1

Nesse momento, ou mesmo depois, não podemos afirmar que Caráusio buscou formar um novo "Império das Gálias" - tal qual fez Póstumo (260-269) no ano 260 -, mas que buscou ser reconhecido como um membro do colegiado imperial, ao lado de Diocleciano e Maximiano Hercúleo.

Essa tentativa de aproximação mostra-se mais latente nas séries monetárias com a legenda PAX AVGG (Paz dos Augustos) - Moeda 3 -, cunhadas após a tentativa frustrada de Maximiano Hercúleo de invadir a Britânia no ano 290. Tal datação, quando contraposta aos textos de Eutrópio e Aurélio Victor, nos permite aventar a existência de um acordo de paz, ou um simples cessar-fogo, entre os imperadores.

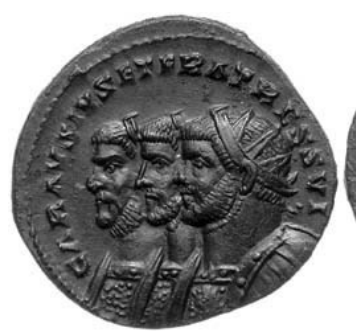

Moeda 3

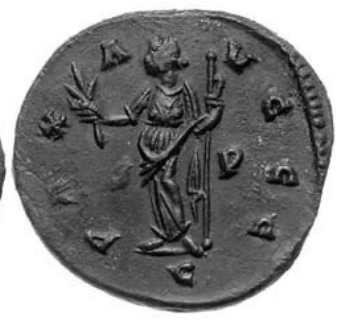


- Datação: Camulodunum, 292-293. AE /

Antoninianus.

- Anverso: Bustos conjugados de Maximiano,

Diocleciano e Caráusio barbados, radiados, encouraçados, à esquerda.

- Legenda: CARAVSIVS ET FRATRES SVI

- Tradução: Caráusio e seus irmãos.

- Reverso: Paz de pé à esquerda, segurando um ramo de oliveira (dir.) e um cetro (esq.).

- Legenda: PAX AVGGG

- Tradução: Paz dos Augustos.

- Exergo: C.

- Indicação: RIC V Maximianus, Diocletian

$\&$ Carausius, 1 .

- Escala: 3:1

Outro dado importante advindo dessa moeda provém de seu anverso. Ao contrário dos demais "imperadores usurpadores" do século III, que ignoravam a existência de outros Augustos, Caráusio ordenou a cunhagem de moedas na qual foram representados os bustos conjugados de si mesmo, Diocleciano e Maximiano, com a legenda CARAVSIVS ET FRATRES SVI (Caráusio e seus irmãos).

Caráusio apresentou suas claras intenções através deste exemplar monetário, manter uma postura de não agressão, de manutenção da paz e, principalmente, da concórdia entre os "Augustos irmãos".

Caso nosso olhar se fixe no reverso deste exemplar monetário, observamos a representação da divindade $\mathrm{Paz}$ com um ramo de oliveira - que demonstra o seu triunfo - e um cetro - que caracteriza o imperium, o poder militar.

Além disso, Caráusio cunhou moedas com os nomes e os símbolos de todas as legiões romanas, como no exemplo da Moeda 4 , na qual se encontra representado o touro, o símbolo da VII Legião - Cláudia Augusta. Nesse caso, Caráusio novamente tenta se representar como um governante legítimo, pois reconhecia a importância de todas as legiões do Império Romano, afinal, a VII Legião - Cláudia Augusta tinha como base não a Britânia, mas a Mésia Superior, então sob administração direta de Diocleciano.
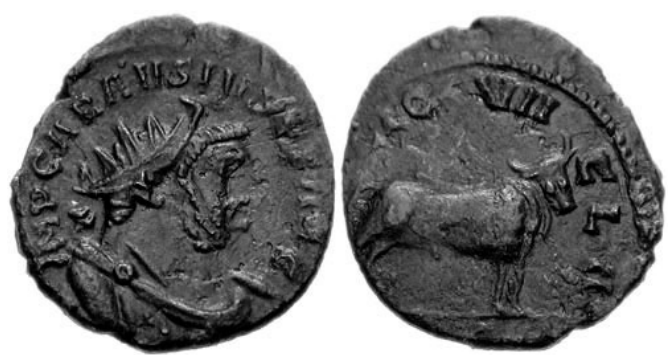

Moeda 4

- Datação: Londres, 287-293. AE / Antoninianus.

- Anverso: Caráusio radiado, colgado, à direita.

- Legenda: IMP C CARAVSIVS P F AVG

- Tradução: Imperador César Caráusio, o Pio, o Feliz, Augusto

- Reverso: Touro de pé à direita.

- Legenda: [LE]G VII CL A[VG]

- Tradução: Sétima Legião - Cláudia Augusta.

- Indicação: RIC V Carausius 75.

- Escala: 3:1

Durante todo o seu governo na Britânia, Caráusio apresentou uma postura de aproximação com os dois outros augustos. E suas séries monetárias sobre a Pax Aug(ustorum), cunhadas nas vésperas da campanha do novo césar Constâncio Cloro, revelam o desejo de Caráusio de não se representar como um imperador seccionista.

A tomada de Boulogne, em 293, marca o fim do governo de Caráusio. Traído por Alecto, o seu principal subordinado, acabou por ser assassinado, antes de fugir para a Britânia, onde buscaria restabelecer as defesas contra a invasão promovida por Constâncio Cloro e Asclepiodoto.

Em relação a Alecto, podemos afirmar que ao assumir a dignidade imperial, manteve a mesma proposta de representação outrora utilizada por Caráusio. Os mesmos temas foram utilizados, conforme podemos inferir da Moeda 5 e da Moeda 6, nas quais Alecto foi representado com a mesma forma onomástica Imperador Alecto o Pio, o Feliz, Augusto; e nas inscrições de reverso nas quais aparecem a VIRTVS AVG (Virtude do Augusto) e, novamente, a PAX AVG (Paz do Augusto). 

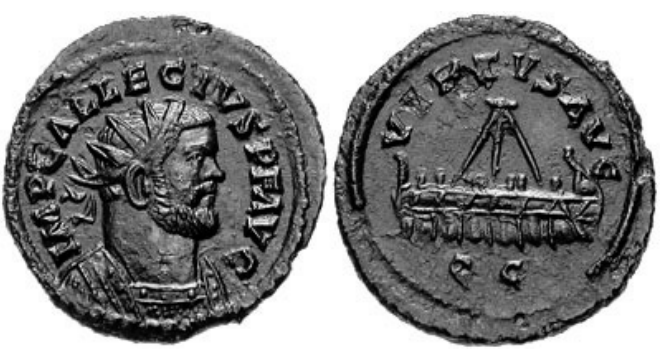

Moeda 5

- Datação: Camulodunum, 293-296. AE /

Quinarius.

- Anverso: Alecto barbado, radiado, encouraçado, à direita.

- Legenda: IMP C ALLECTVS P F AVG

- Tradução: Imperador César Allecto, o Pio, o Feliz, Augusto.

- Reverso: Galera navegando para a esquerda.

- Legenda: VIRTVS AVG

- Tradução: Virtude do Augusto.

- Exergo: QC.

- Indicação: RIC V Allectus, 128.

- Escala: 3:1
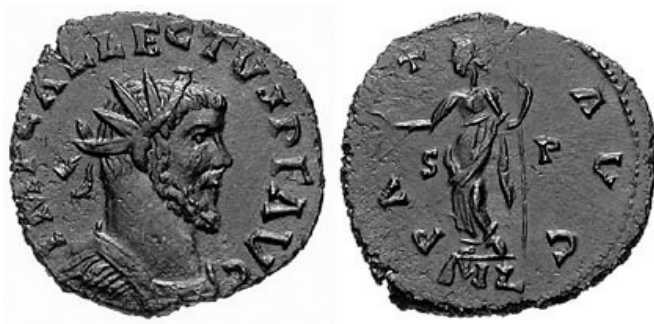

Moeda 6

- Datação: Londres, 294-296. AE / Antoninianus.

- Anverso: Alecto barbado, radiado, encouraçado, à direita.

- Legenda: IMP C ALLECTVS P F AVG

- Tradução: Imperador César Allecto, o Pio, o Feliz, Augusto.

- Reverso: Paz de pé à esquerda, segurando um ramo de oliveira (dir.) e um cetro (esq.).

- Legenda: PAX AVG

- Tradução: Paz do Augusto.

- Exergo: ML.

- Indicação: RIC V Allectus, 28.

Escala: $3: 1$
Igualmente, vários exemplares monetários de Alecto trazem como tipologia de reverso a imagem de uma embarcação, já que, da mesma forma que Caráusio, o poder imperial de Alecto era garantido pela força de seus navios. Nos três anos de seu governo, Alecto buscou resguardar a costa da Britânia, e aguardar pela invasão de Constâncio Cloro, que ocorreu no ano 296.

Por conseguinte, podemos concluir que em sua busca pela legitimação Caráusio se representava como um dos membros de um colegiado triárquico, jamais negando a existência de Diocleciano e Maximiano, pelo contrário, apoiando sua imagem nas dos demais imperadores.

Entretanto, Caráusio jamais foi reconhecido por Diocleciano como um imperador legítimo e, assim, era considerado como um usurpador que, cedo ou tarde, deveria ser eliminado.

Já Alecto, em seu curto período de poder - no qual esteve em guerra constante contra Constâncio Cloro -, buscou seguir os mesmos padrões de representação de Caráusio, sem trazer quaisquer novidades.

\section{Redditor Lucis Aeternae: a campanha de Cons- tâncio Cloro}

Flávio Valério Constâncio, também conhecido como Constâncio Cloro, se tornou imperador em 293, quando Diocleciano empreendeu uma reforma administrativa que levou à formação da Primeira Tetrarquia, que vigorou entre 293 e 305 (Lactâncio. Sobre a morte dos perseguidores. 8, 1-7).

Constâncio era natural da região do Ilírico, na Península Balcânica, sendo conterrâneo de Diocleciano e de Maximiano. Em 293, Constâncio foi elevado de Prefeito do Pretório de Maximiano para o status de César, sendo-lhe conferidas duas missões: a primeira era defender o território da Gália das invasões dos povos germânicos; e a segunda, e mais difícil, era retomar a Britânia para o domínio da Tetrarquia.

Constâncio Cloro foi bem-sucedido em ambas. Em seu primeiro ano como César, derrotou as tropas de Caráusio remanescentes no norte da Gália, em torno da região de Boulogne, o que levou ao motim e à ascensão de Alecto. Em seguida, obteve uma série de vitórias contra os germânicos. 
Nesse ponto é interessante observarmos a diferença entre a documentação contemporânea aos eventos - os Panegíricos Latinos - e os documentos posteriores - os breviários de Eutrópio e de Aurélio Victor -, enquanto que os primeiros são categóricos em conferir a Constâncio o papel de liderança nas operações militares que culminaram com a derrota de Caráusio, os documentos posteriores concedem este papel a seu prefeito do Pretório, Asclepiodoto (Aurélio Victor. De Caesaribus. 39, 42; Eutrópio. Breviário. IX, 22, PLRE I Iulius Asclepiodotus 3).

Com toda a certeza, os Panegíicos Latinos, peças oratórias que entoam louvores ao imperador, jamais creditariam esses grandes feitos a um subordinado, mas ao próprio imperador a ser louvado. Tal limitação, ou mesmo direcionamento do discurso, não ocorreu com os epitomistas posteriores.

Com suas vitórias, Constâncio pôs em prática o papel que o ideário e mística imperiais do sistema da Tetrarquia lhe outorgavam. Segundo as propostas de representação tetrárquica, cada Augusto assumiu um deus do panteão greco-romano como sua divindade tutelar. Diocleciano estava ligado a Júpiter, e Maximiano a Hércules. Os Césares que foram escolhidos, em 293, se tornaram copartícipes dessa natureza divina, sendo considerados também como descendentes dessas divindades.

Constâncio Cloro, nesse sentido, era considerado como um César Hercúleo. Tal signum foi exposto em várias moedas que representavam a tipologia de Hércules performando algum de seus trabalhos - como no caso da Moeda 7. Nesse exemplar monetário, Hércules foi retratado em sua batalha contra a Hidra de Lerna, um monstro marinho e caótico que habitava o lago Lerna, na Argólida (Grimal, 2005:209).
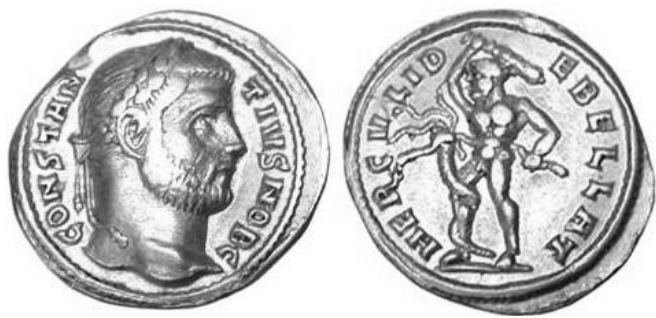

Moeda 7

- Datação: Siscia, 293-294. AV / Aureus.
- Anverso: Constâncio barbado, laureado, à direita.

- Legenda: CONSTANTIVS NOB C

- Tradução: Nobilíssimo César Constâncio.

- Reverso: Hércules de pé, à esquerda, segurando uma clava (dir.), golpeando a Hidra de Lerna.

- Legenda: HERCVLI DEBELLAT

- Tradução: Hércules Destruidor.

- Indicação: RIC VI, 3.

- Escala: 3:1

Do mesmo modo que Hércules derrotou o monstro marinho, Constâncio derrotou o pirata, que baseava o seu poder no domínio sobre o Mar do Norte e o Canal da Mancha. A legenda HERCVLI DEBELLAT (Herculi debellatori, Ao Hércules Destruidor) demonstra tal feito do César Constâncio.

Essa legenda, nesse sentido, é uma dedicatória ao Hercules Destruidor; a Hidra de Lerna era a representação do caos e Hércules era um herói que trazia a ordem, de forma mimética às vitórias de Constâncio, as quais traziam a ordem à Gália - e ao Império Romano -, e seu triunfo sobre Caráusio e Alecto seria uma vitória da ordem sobre o caos.

Nesse mesmo sentido, devemos analisar o medalhão comemorativo da reconquista da Britânia, cunhado na cidade de Augusta Treuerorum (atual Trier, Alemanha), no ano 296 (Moeda 8).

Em seu anverso observamos a efígie de Constâncio Cloro laureado e em vestes militares, como um triunfador. Sua imagem, igualmente, demonstra ser a de um líder militar, em virtude dos trajes militares e da barba. A legenda apresenta a sua fórmula onomástica completa FLAVIVS VALERIVS CONSTANTIVS NOBILISSIMVS CAESAR - Nobilíssimo César Flávio Valério Constâncio.

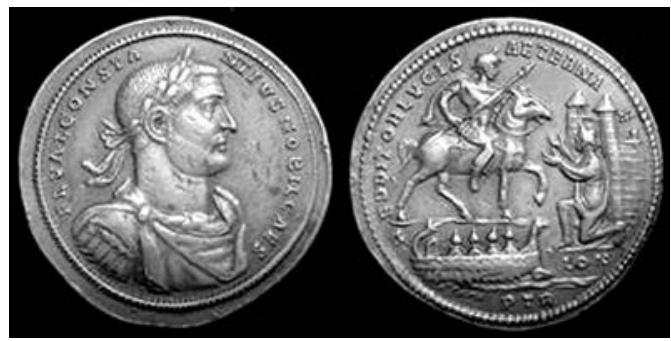

Moeda 8

- Datação: Trier, 296. AV / Aureus. 
- Anverso: Constâncio barbado, laurado, colgado, encouraçado, à direita.

- Legenda: FL VAL CONSTANTIVS NOBIL CAES

- Tradução: Nobilíssimo César Flávio Valério Constâncio.

- Reverso: Príncipe laureado, a cavalo, segurando uma lança (dir.), defronte de uma mulher (em genuflexão) com as mãos erguidas; ao fundo, uma cidade fortificada; abaixo dela, LON. Abaixo do cavalo, uma galera (à dir.), com quatro soldados visíveis.

- Legenda: REDDITOR LVCIS AETERNAE

- Tradução: Restaurador da Luz Eterna.

- Exergo: PTR.

- Indicação: RIC VI Trier 34.

- Escala: 1:1

No que se refere à tipologia de reverso, temos um belo exemplar da arte de cunhagem dos artesãos de Augusta Treuerorum. De um lado, observamos a imagem de Constâncio - a cavalo e empunhando uma lança -, abaixo de sua imagem, uma galera com quatro remadores que se aproximam de uma cidade na qual há uma mulher de braços erguidos - em júbilo e súplica.

Com muita probabilidade, essa mulher é a representação da província Britânia, e a cidade, tal qual podemos inferir da legenda LON, é Londinium. Ademais, era comum nas representações artísticas romanas as cidades e as províncias serem representadas como mulheres.

Essas representações imagéticas presentes nesse exemplar monetário se assemelham à narrativa epidíctica presente no Panegírico Latino (VIII(4) 19. 1), na qual o orador descreve o advento de Constâncio na cidade de Londinium nos seguintes termos:

Então, com toda a razão, assim que desembarcou nesta costa - como um vingador e libertador há muito desejado -, um cortejo triunfal afluiu ante tua majestade, e os bretões, exultantes de alegria, se apresentaram com suas esposas e filhos: veneravam não somente a tua pessoa, que eles viam como descida do céu, como também as velas e os remos dos barcos, que conduziram a tua divindade; estando dis- postos a estender os seus corpos prostrados para que desembarcasses.

Anteriormente, no mesmo Panegírico Latino (PL VIII (4) 4. 3), o autor apresenta a relação entre o poder divino de Constâncio e o restabelecimento da luz sobre as "províncias setentrionais", isto é, as regiões sobre o domínio de Caráusio e Alecto.

Mas, nem o próprio Sol, nem todos os astros guardam os assuntos humanos com tanta constância como vós, que, sem distinguir os dias das noites, iluminais o universo e proveis o bem-estar de todas as gentes, não somente com estes olhos que animam vossa face imortal, como muito mais com os olhos de vossa mente divina; e abençoais com vossa luz salutar não somente as províncias onde o dia nasce, passa e desaparece, como também aquelas da parte setentrional.

A legenda REDDITOR LVCIS AETERNAE (Restaurador da luz eterna), desse modo, demonstra o poder divino e a pietas de Constâncio Cloro, que foi capaz de retirar a província de seu período de trevas. Esse imperador restaurou a luz do domínio romano ao derrotar os usurpadores estabelecidos na Britânia.

A partir desse exemplar monetário e dos Panegíricos Latinos, podemos observar alguns dos argumentos utilizados nos discursos epidícticos, além de certas cerimônias imperiais que demonstravam o fausto imperial da Tetrarquia, em especial celebração do advento.

A temática da luz é uma simbologia concreta nesse medalhão, e que fazia parte dos argumentos empregados pelos oradores quando se referiam às epifanias imperiais tetrárquicas. Esse argumento retórico foi utilizado em outros Panegíricos Latinos, como o proferido no ano 291 (Panegíricos Latinos XI (3) 2,1; 6,6; 12,2; 15,3), e, sobretudo, no Panegírico do ano 296, quando o orador utiliza a metáfora do rompimento das províncias com a luz de Roma, para caracterizar as usurpações (Panegíricos Latinos VIII (4) 10, 1; Christol 1976: 421-434).

Nesse sentido, podemos concluir que a campanha de Constâncio Cloro retirou a Bri- 
tânia das trevas, e ao reincorporar a província ao Império Romano, Constâncio se tornou o restaurador da luz. Para Michel Christol, reddere e restituere, nesse caso, são sinônimos e, por conseguinte, Redditor Lucis Aeternae acaba por significar Restitutor Prouinciae, quando Constâncio restabeleceu novamente a unidade do Império (Christol 1975: 859).

Retornando à representação imagética do reverso, a representação do advento acaba por se entrelaçar com a representação da restauração da província, tal qual depreendemos do discurso do Panegírico Latino. $\mathrm{O}$ advento se tornou um ato de pietas e de restauração, que demonstra o fausto imperial tetrárquico, uma vez que Constâncio, ao reconquistar a Britânia para o Império Romano, estava manifestando a sua pietas e a dos demais imperadores, os quais preocupavam-se com a manutenção da Res publica.

A mensagem presente nessa moeda buscava afirmar o poder do colegiado tetrárquico, uma vez que tal poder era representado como a luz eterna que novamente brilhava sobre a província da Britânia reconquistada por Constâncio Cloro.

SILVA, D.P.; PEDREIRA, E.V. REDDITOR LVCIS AETERNAE: Constantius Chlorus and the Reconquest of Britain. R. Museu Arq. Etn., São Paulo, 22:123-135, 2012.

Abstract: From the discussion about the characteristics of Roman Domination in Britain, we intend to analyze the construction of the imperial rhetoric concerning the reconquest of this province by the emperor Constantius Chlorus in 296. Specially, we will examine the demonstrations of the imperial pomp through the coins and the panegyrics which represent Constantius Chlorus as the redditor lucis aeternae.

Keywords: Roman Empire, Britain, Constantius Chlorus, Carausius

\section{Referências bibliográficas}

\section{Documentação textual e de cultura material}

\section{AURELIUS VICTOR}

1992 De caesaribus. Trad. H.W. Bird. Liverpool: Liverpool University Press.

\section{CASSIUS DIO}

1914 Roman History. v. III. Trad. Earnest Cary.

\section{EUTROPIUS} Harvard: Harvard University Press.

1993 Breviarium. Trad. H.W. Bird. Liverpool: Liverpool University Press.

JONES, A.H.M., MARTINDALE, JOHN., MORRIS, JOHN

1971 The Prosopography of the Later Roman Empire (PLRE). v. I. Cambridge: Cambridge University Press.

\section{JULES CÉSAR}

1926 Guerre des Gaules. Trad. Léopold Albert Constans. Paris: Les Belles Lettres.

LACTANCE

1954 De la mort des persécuteurs. Tr. Jacques Moreau. Paris: Les Belles Letres.

PANEGYRICI LATINI

1994 In Praise of later Roman emperors: the Panegyrici Latini. Trad. C.E.V. Nixon e B. S. Rodgers. Berkeley: University of California Press.

TACITO

1974 Obras menores: Diálogo dos Oradores, Vida de Agricola, A Germânia. Trad. Agostinho da Silva. Lisboa: Livros Horizonte. 


\section{WEBB, PERCY H.}

1933 Probus to Ammandus. In. MATTINGLY, H. SYDENHAM, E.A. The Roman Imperial Coinage (RIC). v. V-2. London: Spink \& Son.

\section{Obras gerais}

\section{ANDO, CLIFFORD.}

2008 The matter of the Gods. Religion and the Roman empire. Berkeley: University of California Press.

BHABHA, HOMI.

1998 O Local da Cultura. Belo Horizonte : Editora UFMG.

CÂMARA, JORGE RICARDO.

2008 Fonis Sulis. A água e o outro mundo celta. Brathair. 8 : 17-26.

\section{CIZEK, EUGEN}

1994 L'Empereur Aurélian et son temps. Paris : Les Belles Lettres.

CHRISTOL, MICHEL

1975 La pietas de Constance Chlore: l'empereur et les provinciaux à la fin du III siècle. Bulletin de la société française de numismatique, 30: 858-861.

1976 Panégyriques et revers monetaires: l'empereur, Rome et les provinciaux à la fin du III siècle. Dialogues d'Histoire Ancienne, 2: 421-434.

2006 L'Empire Romain du IIIe siècle - 192-325 apr. J.C. Paris: Éditions Errance.

CUNLIFFE, BARRY.

1991 Iron Age Communities in Britain. London: Routledge.

2003 The Celts. A very short introduction. Oxford: Oxford University Press.

DAVIDSON, JORGE.

2004 A construção de um espaço para o Império Romano: arquitetura, monumento e ordenamento espacial. Estudos de casos: cidade de Roma e Bretanha Romana - séculos I e II. Niteróio:

GRIMAL, PIERRE. UFF. (Tese de Doutorado em História)

2005 Dicionário da Mitologia Grega e Romana. 5a Ed. Rio de Janeiro: Bertrand Brasil.
HINGLEY, RICHARD.

2006 Boudica. Iron Age warrior queen. London: Hambledon Continuum.

2010 O Imperialismo Romano: novas perspectivas a partir da Bretanha. Campinas,SP: Annablume.

MENDES, NORMA MUSCO.

2006 Romanização e Construção da Paisagem Imperial no Sul da Lusitânia. Phoînix (UFRJ), 13: 231-256.

MENDES, NORMA MUSCO. ARAÚJO, YURI.

2007 Epigrafia, Sociedade e Religião: o caso da Lusitânia. Phoînix (UFRJ), 13: 257-279.

MILLET, MARTIN.

1992 The Romanization of Britain. Cambridge: Cambridge University Press.

2005 Roman Britain. London: Batsford.

POTTER T. W. JOHNS, CATHERINE.

2002 Roman Britain. London. The British Museum Press.

RIVES, JAMES B.

2007 Religion in the Roman Empire. London: Blackwell.

SAID, EDWARD.

1995 Cultura e Imperialismo. São Paulo: Companhia das Letras.

SALWAY, PETER

1993 A History of Roman Britain. Oxford: Oxford University Press.

WATSON, ALARIC.

1999 Aurelian and the third century. London: Routledge.

WEBSTER, GRAHAM.

1993 The Roman Invasion of Britain. London: Routledge.

WILLIAMS, H.P.G.

2004 Carausius: a consideration of the historical, archaeological and numismatic aspects of his Reign. Londres: British Archaeological Reports.

WOOLF, GREG.

2001 Inventing Empire in Ancient Rome. In. ALCOCK, S. E., et alli (org) Empires. Cambridge: Cambridge University Press. 311-322. 